\title{
Cardiovascular Disease and the Changing Face of Global Public Health: A Focus on Low and Middle Income Countries
}

\author{
Pascal Bovet, MD, MPH, ,2 \\ Fred Paccaud, MD, $\mathrm{MSc}^{1,3}$
}

\begin{abstract}
Eighty percent of the global 17 million deaths due to cardiovascular disease (CVD) occur in low and middle income countries (LMICs). The burden of CVD and other noncommunicable diseases (NCDs) is expected to markedly increase because of the global aging of the population and increasing exposure to detrimental lifestylerelated risk in LMICs. Interventions to reduce four main risks related to modifiable behaviors (tobacco use, unhealthy diet, low physical activity and excess alcohol consumption) are key elements for effective primary prevention of the four main NCDs (CVD, cancer, diabetes and chronic pulmonary disease). These behaviors are best improved through structural interventions (e.g., clean air policy, taxes on cigarettes, new recipes for processed foods with reduced salt and fat, urban shaping to improve mobility, etc.). In addition, health systems in LMICs should be reoriented to deliver integrated cost-effective treatment to persons at high risk at the primary health care level. The full implementation of a small number of highly cost effective, affordable and scalable interventions ("best buys") is likely to be the necessary and sufficient ingredient for curbing NCDs in LMICs. NCDs are both a cause and a consequence of poverty. It is therefore important to frame NCD prevention and control within the broader context of social determinants and development agenda. The recent emphasis on NCDs at a number of health and economic forums (including the September 2011 High Level Meeting on NCDs at the United Nations) provides a new opportunity to move the NCD agenda forward in LMICs.
\end{abstract}

Key Words: Cardiovascular disease, noncommunicable disease, global public health, low and middle income countries, health systems, prevention, policy, intersectoral action

\footnotetext{
${ }^{1}$ Institute of Social and Preventive Medicine (IUMSP), Lausanne University Hospital, Lausanne, Switzerland

${ }^{2}$ Ministry of Health, Victoria, Seychelles

${ }^{3}$ Swiss School of Public Health, Zurich, Switzerland
}

Corresponding Author Contact Information: Pascal Bovet at pascal.bovet@chuv.ch; Institute of Social and Preventive Medicine (IUMSP), Route de la Corniche 10, CH-1010 Lausanne, Switzerland. 
Recommended Citation: Bovet P, Paccaud F. Cardiovascular disease and the changing face of global public health: a focus on low and middle income countries. Public Health Reviews. 2012;397-415.

\section{INTRODUCTION}

Cardiovascular disease (CVD) is the leading cause of death with 17 million deaths worldwide from a total of 57 million annually ${ }^{1}$ and 80 percent of all CVD deaths now occur in low and middle income countries (LMIC). While the CVD epidemic is receding in high income countries, CVD mortality rates tend to be higher in many LMICs (e.g., up to 300-600 CVD deaths per 100,000 population) than in Western countries ${ }^{1}$ and the burden is expected to increase further (Figure 1). We focus in this paper on the main noncommunicable diseases (NCD) (i.e., CVD, cancers, diabetes, and chronic respiratory disease ${ }^{1,2}$ ). These four diseases contribute to the largest share of all deaths worldwide (Figure 1) and they are largely attributable to four common preventable risk factors (tobacco, unhealthy diet, excessive alcohol use and physical inactivity). ${ }^{1-5}$ The focus on these NCDs does not diminish the need to also address other chronic diseases and conditions that are major contributors to the disease burden globally or in certain countries (e.g., mental health, violence, car accidents, hemoglobinopathies, rheumatic heart diseases, liver diseases, etc).

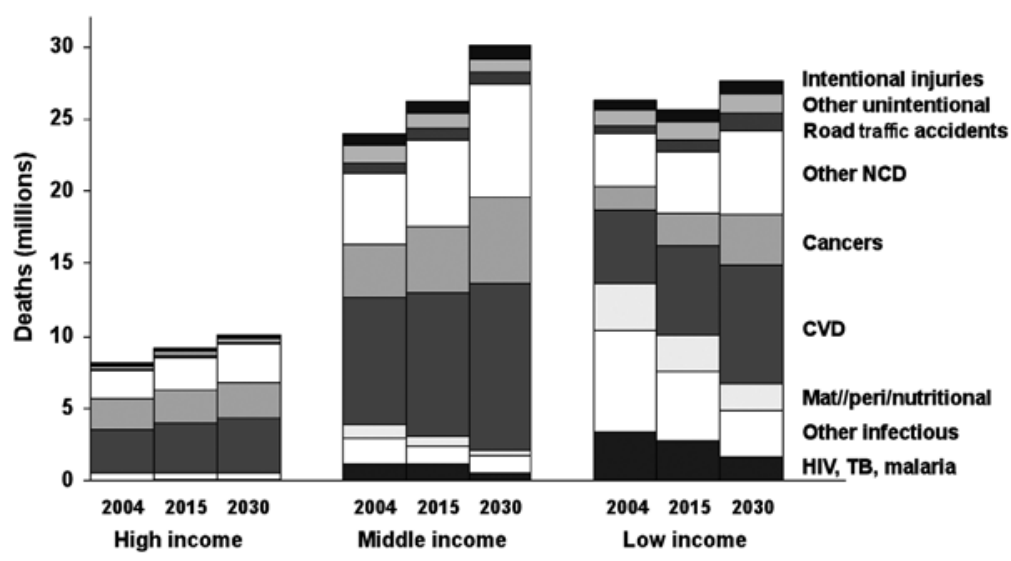

Fig. 1. Projected deaths by cause for high-, middle- and low-income countries.

Source: World Health Organization ${ }^{29}$ 
For the sake of simplicity, and consistent with many current documents on global health, ${ }^{1-5}$ we categorize countries according to their gross national income (GNI) per capita: less than USD \$1,005 for low income countries (LIC), USD \$1006-3975 for lower middle income countries, USD \$397612,275 for upper middle income countries, and USD \$12,276 and greater for high income countries (HIC). ${ }^{6}$ Admittedly, development status, social conditions, physical environments and disease patterns can differ considerably both between and within GNI categories, which underlie that health related priorities may vary largely between particular countries.

In this paper we argue that NCDs constitute a major global public health crisis with critical challenges to both national health systems and policy development. ${ }^{7}$ Although resources allocated to NCDs is still low in most LMICs, the good news is that the epidemic of NCDs in the LMICs is now better quantified and visible and that several recent major developments have taken place in the international scene to spearhead and accelerate improved public health responses at the global and national levels.

\section{THE MOUNTING BURDEN OF CVD AND CHRONIC DISEASES IN LMICs}

The increasing burden of NCDs in LMICs is predicted by the epidemiologic transition theory (e.g., Omran 1971, reprinted in $2005^{8}$ ). The epidemiological transition posits that disease patterns change along with socio-economic development (Figure 2), as a result of improved control of infectious diseases, aging of the populations, and globalization of risks such as tobacco use, unhealthy diet, and sedentary habits. In the last stage of the epidemiologic transition, which typically prevails in Western countries, CVD recedes as a result of improved diet, healthier lifestyles and more effective treatment among large segments of the population. ${ }^{9}$

It is difficult to get reliable data on CVD morbidity and mortality in LMICs because of the lack of vital statistics and other adequate systems to register causes of deaths in the entire population in most LMICs. Furthermore, the ascertainment of causes of deaths remains a technical challenge in LMICs where such data are available. ${ }^{10}$ Therefore, the emphasis is on surveillance of CVD risk factors at the population level. The focus on risk factors is adequate because current levels of risk factors predict future trends of CVD events, while current CVD morbidity or mortality data tend to reflect past levels of risk factors. Reliable information on risk factors requires population-based surveys repeated regularly over time. The World Health Organization (WHO) has developed standardized 
survey instruments for surveys of risk factors in adults (STEPwise approach to serveillance - STEPS*), and in children (Global School-based Student Health Survey - GSHS ${ }^{* *}$ ). Surveillance data are necessary to guide programs and policy at the national level ${ }^{11}$ and for comparison of risk factors between countries and regions. ${ }^{12}$ Strengthening health information systems is therefore a priority for the prevention and control of NCDs in LMICs.

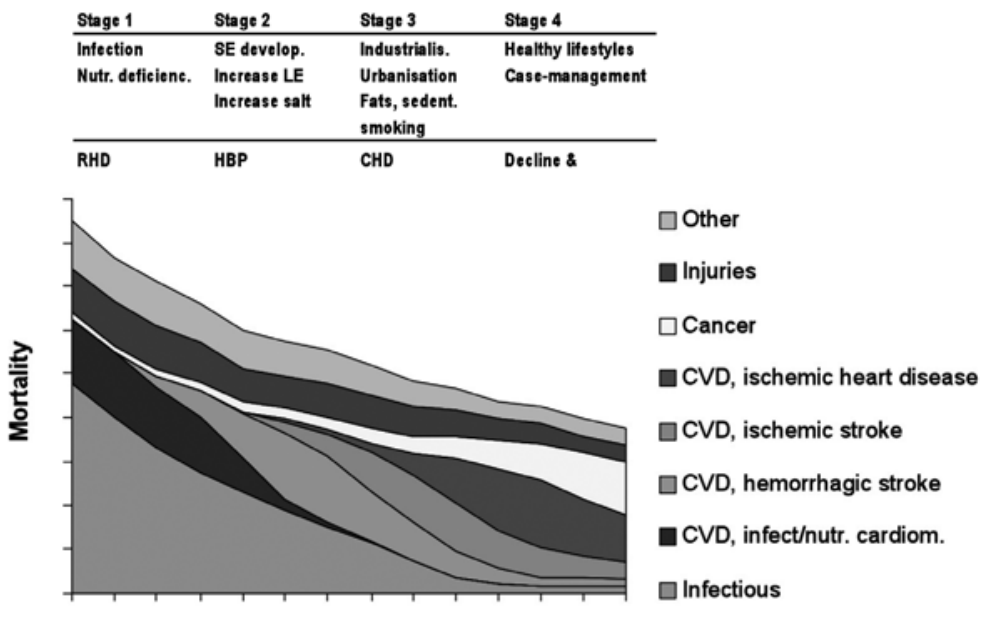

Time (proxy: life expectancy, development)

Fig. 2. Decreasing mortality rates and changing patterns of causes of deaths along stages of the epidemiologic transition.

The global epidemiological situation of CVD risk factors has been quantified recently based on a pooled analysis of all available data from published and non published population-based surveys. ${ }^{13-16}$ Based on these data and modeling techniques, estimates of CVD risk factor levels can be obtained for all countries. ${ }^{* * *}$ The prevalence of overweight and diabetes are increasing in all countries including in LMICs. Blood pressure and blood cholesterol are decreasing in high income countries, but increasing in many (but not all) LMICs. ${ }^{17}$ Other sources of data show that the prevalence of

\footnotetext{
* http://www.who.int/chp/steps/en/ (Accessed 20 May, 2012)

** http://www.who.int/chp/gshs/en/ (Accessed 20 May, 2012)

*** http://www.who.int/gho/ncd/en/index.html and http://www.who.int/gho/ncd/risk_factors/ overweight/en/index.html (Accessed 20 May, 2012)
} 
tobacco use is decreasing in high income countries but increasing in most LMICs (but not all), which echoes better tobacco control policy in the former than the latter.

The demographic transition (i.e., the postponement of age at death) is and will remain the main driver of the increasing burden of CVD and other NCDs in LMICs during the next few decades, ${ }^{18}$ as shown in Figure 3. Because the likelihood to develop CVD and other NCDs increase strongly with age, the number of persons with NCD will inevitably increase along with the increasing and aging populations in LMICs. It is therefore a great challenge to oppose this large increase in NCDs, attributable to demographic pressure, with prevention strategies that aim to reduce risk factors of CVD in the population. This observation should remind us to avoid setting unrealistic goals for prevention programs and to plan increasing health care resources for CVD management during the next few decades (e.g., training of health professionals, hospital beds for CVD, equipment, medications, etc.).

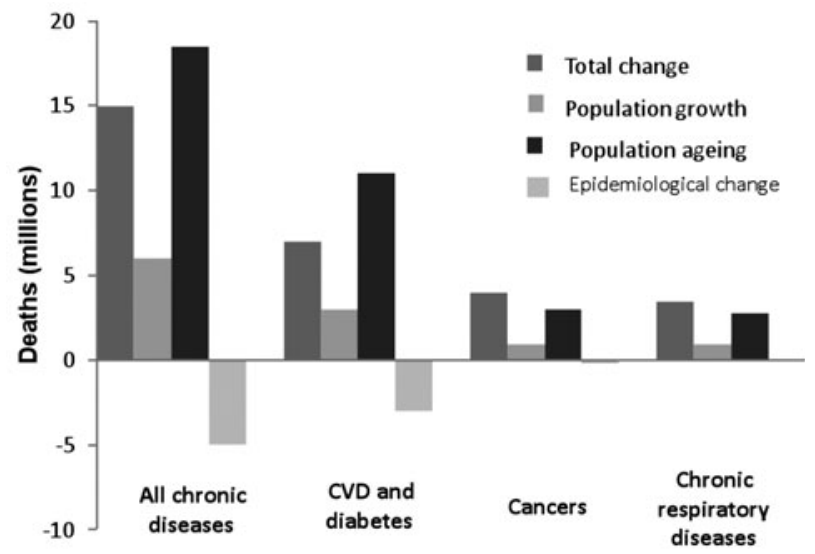

Fig. 3. Decomposition of projected change in numbers of chronic disease deaths into demographic and epidemiological components, in 23 selected countries, 20052030.

Source: Abegunde DO, et al. ${ }^{18}$

Few LMICs have managed to comprehensively enumerate both the entire population distribution and all deaths occurring in the entire population in order to monitor the age-standardized CVD mortality rates over time. In the Seychelles (an upper middle income small island state in the African region), where these figures have been available, the age 
adjusted mortality from stroke, myocardial infarction and all CVD has decreased by as much as 40 percent between 1989 and $2010,{ }^{19}$ consistent with vigorous prevention programs and policy (e.g., comprehensive tobacco legislation) and universal free health care. This large decrease has succeeded in containing the total number of stroke deaths over time in spite of the largely increasing and aging population. Similar decreases in age-adjusted CVD mortality rates have been found in a few South American countries. ${ }^{20}$ Although less favorable CVD trends may still prevail in a number of other LMICs, findings of a decline in age-adjusted rates of CVD in some LMICs suggest that the anticipated increase in the CVD burden can be curbed, and eventually reversed, when considering the large potential for scaling up cost-effective interventions for the prevention and control of NCDs in LMICs.

\section{IMPACT ON INDIVIDUALS, HOUSEHOLDS, HEALTH SYSTEMS AND ECONOMY}

CVD and other chronic diseases are both a cause and a consequence of poverty, as illustrated in Figure 4. ${ }^{1,21}$ Poor living conditions expose individuals to an environment that is not conducive to healthy lifestyles and augments the risk of NCDs. In poor areas, shops tend to sell more energydense foods, alcohol and cigarettes than fruit and vegetables and there are fewer safe green areas needed to promote physical activity. Furthermore, public health programs to address NCDs are weak in these areas and access to adequate health services is limited. Inversely, CVD and chronic diseases contribute to poverty. The high expenses for long-term clinical management of CVD and other NCDs are a frequent cause of impoverishment, particularly in the many LMICs where most of the health care expenditures are born by out-of-pocket payments. ${ }^{22}$ This has major collateral consequences at the household level, ${ }^{4}$ and it is now widely recognized that the rise of NCDs is a major barrier to social and economic development. ${ }^{23}$ This emphasizes the need to address social determinants and equity issues, including universal access to basic health care for NCDs, when designing programs and health policy to reduce NCDs in LMICs. ${ }^{1,23}$

The cost of inaction in the area of NCDs in LMICs would be huge at a macroeconomic level. For every ten percent rise in mortality from NCDs, the yearly economic growth is estimated to be reduced by 0.5 percent. ${ }^{24} \mathrm{In}$ China alone, it has been estimated that reducing CVD mortality by one percent per year over a 30-year period (2010-2040) could generate an economic value equivalent to 68 percent of the country's real GDP in 
2010 - more than USD $\$ 10.7$ trillion at purchasing power parity. ${ }^{25}$ The yearly economic loss due to NCDs in China (approximately $50 \%$ of it is related to CVD) is approximately equivalent to four percent of the current annual output of LMICs. ${ }^{5}$ On a per-person basis, the annual economic losses are estimated to range between USD \$25 in low income countries to USD $\$ 139$ in upper middle income countries. ${ }^{5}$

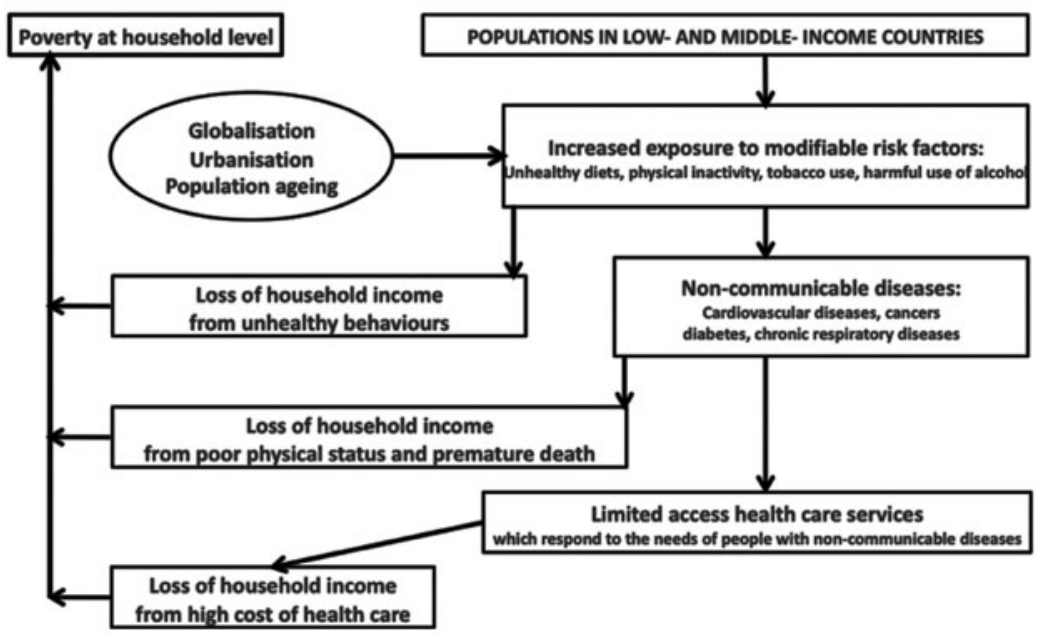

Fig. 4. Relationship between NCDs and poverty.

Source: Adapted from World Health Organization ${ }^{1}$

With regard to the response to this challenge, it is estimated that the annual cost per capita for implementing a set of highly cost-effective interventions could amount to only USD \$1 for population-based measures aimed at reducing tobacco and harmful use of alcohol and to another $\sim$ USD $\$ 2$ for the scaling up of multi-drug therapy for all persons at high CVD risk, as shown in Table 1.1,4 From a broader perspective, the World Economic Forum ranks NCDs in the top five global threats to global economic development worldwide. ${ }^{26}$ These findings illustrate the mounting challenge of NCDs for national development in LMICs. Recent seminal economic documents on these issues provide timely information to advocate that higher priority should be given to the prevention and control of NCDs in LMICs. 
Table 1

Estimated yearly cost per head (in USD) of a package

for prevention of cardiovascular disease and other main chronic diseases

\begin{tabular}{l|l|l|l|l|l}
\hline & Brazil & China & India & Mexico & $\begin{array}{c}\text { South } \\
\text { Africa }\end{array}$ \\
\hline $\begin{array}{l}\text { Tobacco use-excise tax increase, } \\
\text { information and labeling, smoking } \\
\text { restrictions and advertising bans }\end{array}$ & 0.25 & 0.14 & 0.16 & 0.54 & 0.60 \\
\hline $\begin{array}{l}\text { Harmful alcohol use-excise tax } \\
\text { increase, advertising bans, restricted } \\
\text { access }\end{array}$ & 0.15 & 0.07 & 0.05 & 0.24 & 0.29 \\
\hline $\begin{array}{l}\text { Unhealthy diet and physical activity- } \\
\text { mass media campaigns, food taxes } \\
\text { and subsidies, nutritional information/ } \\
\text { labeling, and marketing restrictions } \\
\text { (this analysis) }\end{array}$ & 0.48 & 0.43 & 0.35 & 0.79 & 0.99 \\
\hline $\begin{array}{l}\text { Reduced dietary salt (mass media } \\
\text { campaigns, regulation of the food } \\
\text { industry) }\end{array}$ & 0.12 & 0.05 & 0.06 & 0.22 & 0.15 \\
\hline $\begin{array}{l}\text { Combination drug therapy for high- } \\
\text { risk individuals }\end{array}$ & 1.89 & 1.02 & 0.90 & 2.74 & 1.85 \\
\hline $\begin{array}{l}\text { Total cost per head of intervention set } \\
\text { (excluding cost synergies or future } \\
\text { treatment cost savings) }\end{array}$ & 2.89 & 1.72 & 1.52 & 4.53 & 3.88 \\
\hline
\end{tabular}

Source: Cecchini M, et al. ${ }^{55}$

These issues are important considering that less than three percent of the official development assistance for health currently goes to NCDs while NCDs represent 62 percent of the global mortality in LMICs. ${ }^{27}$

\section{DEBUNKING OLD MYTHS ABOUT CVD}

Prioritizing CVD prevention and control in LMICs has been hampered by several fallacious but tenacious myths for decades and ten widespread misunderstandings have been critically addressed in a key WHO report on NCDs. ${ }^{28}$ CVD has been considered a disease of the old age. However, 29 percent of all CVD deaths occur among people under the age of 60 in LMICs, compared to 13 percent in high income countries. ${ }^{1,29}$ It has been 
believed that CVD mainly affects wealthy people. Yet, CVD disproportionately affects the poor in most countries, including in LMICs. ${ }^{1,30}$ Several major risk factors of CVD are more prevalent among the poor (e.g., tobacco, poor diet and obesity) and the poor also have less access to health services for management of NCDs. The relationship between NCD and poverty is discussed in more detail in a later paragraph. Another myth posits that CVD results from one's own individual lifestyle choices and that there is no one to blame but those individuals who indulge in unhealthy behaviors. The truth is that personal responsibility can be fully effective only when individuals have equitable access to a healthy lifestyle and they are supported to make healthy choices.

Another myth is that prevention and control of CVD is less costeffective than prevention and control of infectious diseases. This belief may have arisen because CVD management in high income countries has largely relied on expensive clinical management at the individual level. However, several highly cost-effective interventions for the prevention and control of NCDs have been well documented-particularly for CVD at both the individual and population levels, ${ }^{31,32}$ as discussed later. It has also been alleged that the scarce resources available for health should be exclusively allocated to the control of communicable diseases in LMICs. However most LMICs already experience a double burden of infectious diseases and chronic diseases and NCDs are strongly associated with poverty and development. ${ }^{4,26,33-35}$ Furthermore, prevention and control of NCDs can markedly improve control of infectious diseases and subsequently accelerate the achievement of millennium development goals related to infectious diseases. ${ }^{24}$

\section{PREVENTION AS BOTH AN OPPORTUNITY AND A MUST}

Although a few community-based trials have been conducted successfully in high income countries ${ }^{36}$ the conduct of such trials remain a challenge because interventions must target several risk factors simultaneously and include both population wide and individual-based interventions. Evidence must therefore also build on other data sources (e.g., cross-country comparison, quasi experiments and modeling data). For example, it was shown that CVD mortality could decrease by up to 20 percent within months of implementation of a ban on smoking in enclosed public places ${ }^{37}$ and CVD mortality fell largely and quickly following major changes in nutrition at the population level resulting from external circumstances. ${ }^{38,39}$ 
Intervention on four modifiable risk factors (tobacco use, poor diet, excess alcohol and sedentary habits) has the potential to substantially reduce the burden of CVD, diabetes, cancers, and chronic respiratory diseases. ${ }^{7,40}$ Evidence from high income countries suggests that favorable changes on these few main behaviors can explain 44-76 percent of the decline in coronary heart disease (CHD) mortality in Western countries while treatment explains approximately $23-47$ percent. ${ }^{41}$ This "4 by 4 " approach is central to the WHO Plan of Action for the Prevention and Control of NCDs. ${ }^{2}$

There are two main strategies for prevention of NCDs: the population wide interventions and the individual based interventions. Among interventions targeting the entire population, structural measures aimed at making the healthy choice the easy choice for individuals are particularly attractive. Importantly, structural interventions may not need explicit cooperation of individuals in order to produce the expected lifestyles changes (e.g., improved diet through reformulation of manufactured foods to reduce trans fats or salt). Another advantage of population-wide interventions is that they can be implemented at low cost and some of them can even generate revenue (e.g., taxes on tobacco and on alcohol). On the other hand, individual-level strategies often incur very high costs (e.g., lifelong treatment of hypertension or diabetes), which emphasizes the need to carefully select interventions (e.g., screening strategies, medications, etc.) that are both affordable and highly cost-effective. Selecting interventions based on cost-effectiveness criteria is also important to avoid that the provision of services is left at the mercy of local and global commercial interests.

\section{POPULATION-BASED INTERVENTIONS: THE NEED FOR MULTI- SECTORAL ACTION}

To a large extent, abnormal behaviors in modern societies (e.g., overeating, excess salt intake, low physical activity, tobacco use) are "normal responses to abnormal environments" ${ }^{42}$ Changes are unlikely to take place through individual information campaigns and interventions directed to patients at the health care level alone. Instead, a whole governmental approach is needed that involves all sectors, including national and local governments, industry and communities (Figure 5). For example, the most effective measures for tobacco control include increased taxes on tobacco products, bans on smoking in enclosed public places and on tobacco advertising, and compulsory health warnings on cigarette packets (Table 2). These measures 
are prominent provisions of the WHO Framework Convention on Tobacco Control (FCTC), a legally binding treaty ratified by more than 175 countries. Similarly, improved diet will require reformulation of manufactured foods by the industry to lower the content of salt, saturated fats, trans fats, sugar and calories (Table 2). Measures to promote physical activity are also needed, including well-lit and safe green areas and sidewalks and dedicated lanes for bikes and buses. All these measures imply the involvement of many sectors. Several countries have implemented comprehensive tobacco control policy ${ }^{43}$ and an increasing number are developing effective salt reduction programs (e.g., United Kingdom, Australia, Finland, Japan, South Africa, etc.). ${ }^{44}$ Multilevel programs to promote physical activity have been successful in several LMICS (e.g., "Agita São Paulo" or "Ciclovía" in many countries ${ }^{4,45}$ ). Examples of ongoing comprehensive community based programs include many cities within the EPODE European Network ${ }^{* *}$ and the Foresight program ${ }^{* * *}$ to fight obesity in the United Kingdom.

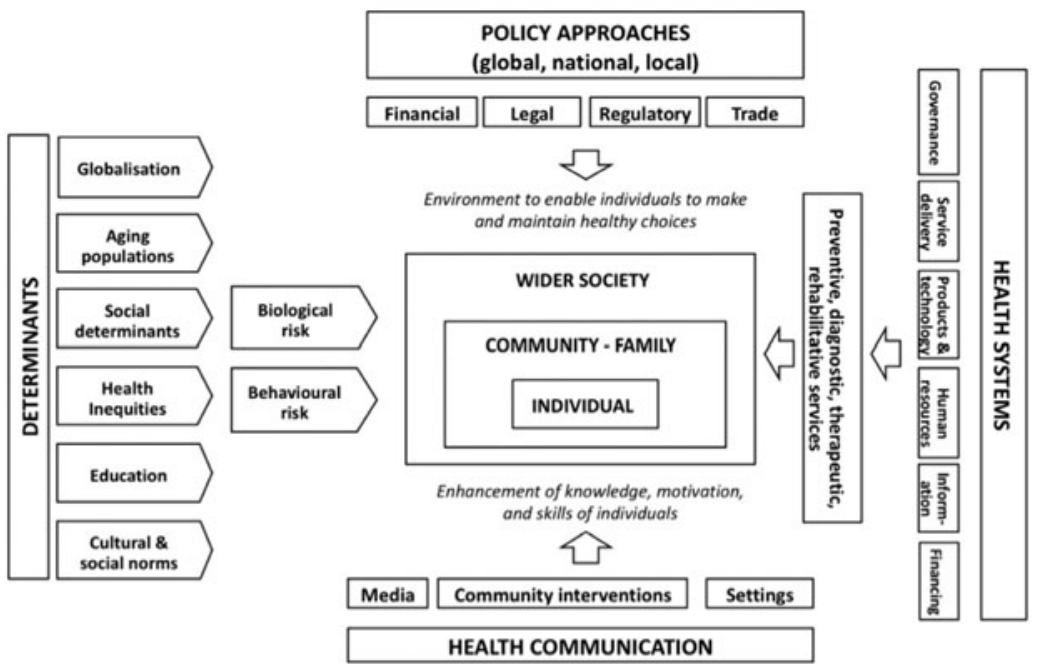

Fig. 5. Comprehensive strategy to address cardiovascular disease.

Source: Adapted from Institute of Medecine ${ }^{53}$

\footnotetext{
* http://bit.ly/r4fJSu (Accessed 20 May, 2012)

** http://www.epode-european-network.com/ (Accessed 20 May, 2012)

*** http://www.bis.gov.uk/foresight (Accessed 20 May, 2012)
} 
Table 2

"Best buy" interventions for prevention of cardiovascular disease and major chronic diseases

\begin{tabular}{|c|c|}
\hline \multicolumn{2}{|r|}{ Population based interventions addressing NCD risk factors } \\
\hline Tobacco use & $\begin{array}{l}\text { - Tax increases } \\
\text { - Smoke-free indoor workplaces and public places } \\
\text { - Health information and warnings about tobacco } \\
\text { - Bans on tobacco advertising, promotion and sponsorship }\end{array}$ \\
\hline $\begin{array}{l}\text { Harmful alcohol } \\
\text { use }\end{array}$ & $\begin{array}{l}\text { - Tax increases } \\
\text { - Restricted access to retailed alcohol } \\
\text { - Restrictions and bans on alcohol advertising and marketing }\end{array}$ \\
\hline $\begin{array}{l}\text { Unhealthy diet } \\
\text { and physical } \\
\text { inactivity }\end{array}$ & $\begin{array}{l}\text { - Reduced salt intake in food through mass media campaigns and } \\
\text { reduced salt content in processed foods } \\
\text { - Replacement of trans fats with polyunsaturated fats } \\
\text { - Public awareness through mass media on diet and physical activity }\end{array}$ \\
\hline \multicolumn{2}{|c|}{ Individual based interventions addressing NCDs in primary health care } \\
\hline $\begin{array}{l}\text { CVD and } \\
\text { diabetes }\end{array}$ & $\begin{array}{l}\text { - Multi-drug therapy for people who have had a heart attack or stroke or } \\
\text { who are at a high risk ( }>30 \%) \text { of CVD event in next } 10 \text { years } \\
\text { - Treatment of heart attacks with aspirin }\end{array}$ \\
\hline Cancer & $\begin{array}{l}\text { - Hepatitis B immunization to prevent liver cancer (already scaled up) } \\
\text { - Screening and treatment of pre-cancerous lesions to prevent cervical } \\
\text { cancer }\end{array}$ \\
\hline
\end{tabular}

Source: World Health Organization ${ }^{34}$

\section{INDIVIDUAL LEVEL INTERVENTIONS: THE CASE FOR MULTI- DRUG THERAPY}

Long-term care of asymptomatic conditions (e.g., hypertension, diabetes) is challenging. In a study in Dar es Salam (Tanzania), less than one third of persons identified to have hypertension during a screening performed at their homes attended a health center after having been advised to do so and less than three percent were taking an antihypertensive treatment 12 months later. ${ }^{46}$ In Seychelles, less than 30 percent of newly hypertensive patients regularly took their antihypertensive medication after one year of treatment, despite free health care. ${ }^{47}$ Heath systems need therefore to be strengthened in order to be able to supply adequate services for chronic conditions at the 
primary health care level. A number of issues need be addressed at all levels of the six building blocks of heath systems ${ }^{48}$ including integration of essential care for NCD at the primary care level (e.g., "whole patient" approach rather than competing vertical programs), moving toward universal coverage to reduce out-of-pocket payment by patients, improved efficiency, formulation of simple guidelines, adequate training, task shifting, etc. The use of a combination of several off-license medications has been advocated ${ }^{4,5,7,18,34}$ and this is a "best buy" intervention for CVD prevention at the individual level (Table 2). This strategy (e.g., "polypill") may have several advantages over the usual "single risk factor" approaches including improved adherence, lower cost, simplified treatment schedules, and partial task shifting from doctors to nurses. ${ }^{49,50}$ Around five to ten percent of all adults aged 35-64 years would need to be treated ${ }^{51}$ at a cost of USD \$1-2 per capita per year (around USD \$12 billion per year in all LMICs). Table 1 is a reminder that despite being particularly cost-effective, individual-level risk reduction strategies tend to incur high total cost as compared to other "best buy" population wide interventions. ${ }^{34}$

\section{PRIORITY INTERVENTIONS FOR LMICS - BEST BUYS}

Compelling evidence on effective interventions for the prevention of NCDs at both the population and individual levels has become available recently. ${ }^{1,752-54}$ Those interventions that are also feasible, affordable, and scalable at the entire population level have been labeled "best buys" by the WHO and are listed in Table 2.1,5,7,34

Affordability is essential when considering that total annual expenditures for health care range from more than USD $\$ 5000$ in several high income countries to less than USD $\$ 50$ per capita in many low income countries. In LMICs, it has been estimated that two population-wide interventions (a $15 \%$ reduction of salt intake and the implementation of the four key provisions of the Framework Convention on Tobacco Control) could prevent 14 million premature deaths over ten years. As shown in Table 1, these interventions could be implemented for less than USD $\$ 0.40$ per person per year in LMICs. ${ }^{18} \mathrm{~A}$ few other interventions ("good buys") could deliver substantial additional health gains (e.g., communication strategies to improve awareness about the benefits of healthy eating and physical activity, fiscal measures that increase the price of unhealthy food and reduce of cost of healthy foods, and regulatory measures that improve nutritional information or restrict the marketing of unhealthy foods to children $^{1,55}$ ). 
With regards to implementation, clear goals, targets and indicators alongside with a plan of action should be set at the national level to spearhead a timely and coordinated response and elicit appropriate resources. ${ }^{7,56} \mathrm{~A}$ high level multi-sector committee is needed to oversee the effective implementation of interventions in many sectors (i.e., beyond the health sector). Strong leadership from the health sector is needed to champion policy tradeoffs that favor health over political and commercial interests, particularly for interventions that fall under other sectors. Successful intersectoral action requires focused leadership, effective partnerships, transparent accountability, research, monitoring and evaluation., ${ }^{2,7}$

\section{THE POLITICAL DECLARATION OF THE UNITED NATIONS HIGH LEVEL MEETING ON NCDS: A NEW OPPORTUNITY TO MOVE THE NCD AGENDA FORWARD}

A milestone for the global response to NCDs was achieved in New York on 19-20 September 2011 with the adoption of the Political Declaration of the High Level Meeting (HLM) on the Prevention and Control of NCDs..$^{57,58}$ This historical event opened up new opportunities to move the NCD agenda forward. ${ }^{56}$ Because a number of high level meetings in all regions took place before the HLM and equally important meetings will follow to ensure implementation, the "power of the process" of this event has generated an unprecedented interest for NCDs and was instrumental in making NCDs appear on the radar of policy makers in LMICs. Several seminal reports were produced for this occasion ${ }^{4,5,7,25,33,34}$ to advocate the need to address NCDs in LMICs and to synthesize the main challenges and opportunities related to NCD prevention along both the health and development agendas.

The political declaration offers affirmation, empowerment, coordination, and continuity for NCD prevention and control nationally and globally. ${ }^{59}$ Examples of provisions include that the consumption of tobacco and alcohol will be curtailed through national taxation and marketing restrictions; the use of saturated fats, trans fats, salt, and sugar will be constrained through regulation and negotiation; public campaigns will target the four modifiable risk factors (tobacco use, unhealthy diet, physical inactivity, harmful use of alcohol) and their attendant disease groups; the WHO, the designated coordinator of the global response to the NCDs, will develop a comprehensive global monitoring framework; and the UN Secretary General will consider relevant partnerships, monitor the realization of HLM commitments, and report on progress in the prevention and control of NCDs. ${ }^{59}$ 


\section{CONCLUSIONS}

It is now well recognized that the emergence of CVD and other NCDs in LMICs is a major global public health challenge. The increasing burden of NCDs worldwide is largely attributable to the demographic transition, which causes a large increase in the numbers of the middle-aged and older people who are at increased risk of NCDs.

The good news is that we now know of a number of effective strategies to prevent CVD and NCDs. Interventions to reduce four common behavioral risk factors (tobacco use, unhealthy diet, low physical activity and excess consumption of alcohol) are at the core of effective primary prevention of the main NCDs at the population level. These behaviors are best improved primarily through structural interventions (e.g., taxes on unhealthy products, reformulation of manufactured food, shaping urban environments to encourage physical activity). In addition, health systems in LMICs should be reoriented to deliver appropriate management to high risk individuals with emphasis on efficient and integrated supply of costeffective treatment at the primary health care level.

Several interventions at both the population and individual levels are cost-effective and those that are feasible, affordable and scalable are regarded as "best buys". The full implementation of these "best buy" interventions might be the necessary and sufficient ingredients for curbing NCDs in LMICs. The Political Declaration of the United Nations High Level Meeting on NCDs and a number of recent reports from health, economic and development organizations highlight the need to implement these "best buy" interventions with high priority, which provides a new opportunity to move the NCD agenda forward in LMICs.

\section{Acronyms list:}

$\mathrm{CVD}=$ Cardiovascular Disease

$\mathrm{GNI}=$ Gross national income

HLM = United Nations High Level Meeting on the Prevention and Control of NCDs

LMICs $=$ Low and middle income countries

$\mathrm{NCD}=$ Noncommunicable disease

Conflicts of Interest: None declared. 


\section{REFERENCES}

1. World Health Organization. Global status report on noncommunicable diseases 2010. Geneva: WHO; 2011.

2. World Health Organization. 2008-2013 Action plan for the global strategy for the prevention and control of noncommunicable diseases. Geneva: WHO; 2008.

3. United Nations. Political declaration of the High-level Meeting of the General Assembly on the Prevention and Control of Non-communicable Diseases Resolution adopted by the General Assembly. New York: UN; 2011.

4. The World Bank. The growing danger of non-communicable diseases - Acting now to reverse course. Washington DC: The World Bank; 2011.

5. World Health Organization and World Economic Forum. From burden to "best buys": reducing the economic impact of non-communicable diseases in lowand middle-income countries. Geneva: WHO and World Economic Forum; 2011.

6. The World Bank. How we classify countries? Washington DC: The World Bank; 2011. Available from URL: http://data.worldbank.org/about/countryclassifications (Accessed 13 May, 2012).

7. Beaglehole R, Bonita R, Horton R, Adams C, Alleyne G, Asaria P, et al. Priority actions for the non-communicable disease crisis. Lancet. 2011;377:1438-47.

8. Omran AR. The epidemiologic transition: a theory of the epidemiology of population change. 1971. Milbank Q. 2005;83:731-57.

9. Olshansky SJ, Ault AB. The fourth stage of the epidemiologic transition: the age of delayed degenerative diseases. Milbank Q. 1986;64:355-91.

10. Bovet P, Shamlaye C, Paccaud F. Stroke mortality in the Seychelles: methodological issues. Lancet Neurol. 2009;8:700; author reply 700.

11. Bovet P, Viswanathan B, Shamlaye C, Romain S, Gedeon J. Addressing noncommunicable diseases in the Seychelles: towards a comprehensive plan of action. Glob Health Promot. 2010;17(2 Suppl):37-40.

12. Guthold R, Louazani SA, Riley LM, Cowan MJ, Bovet P, Damasceno A, et al. Physical activity in 22 African countries: results from the World Health Organization STEPwise approach to chronic disease risk factor surveillance. Am J Prev Med. 2011;41:52-60.

13. Danaei G, Finucane MM, Lu Y, Singh GM, Cowan MJ, Paciorek CJ, et al. National, regional, and global trends in fasting plasma glucose and diabetes prevalence since 1980: systematic analysis of health examination surveys and epidemiological studies with 370 country-years and 2.7 million participants. Lancet. 2011;378:31-40.

14. Farzadfar F, Finucane MM, Danaei G, Pelizzari PM, Cowan MJ, Paciorek CJ, et al. National, regional, and global trends in serum total cholesterol since 1980: systematic analysis of health examination surveys and epidemiological studies with 321 country-years and 3.0 million participants. Lancet. 2011;377:578-86. 
15. Finucane MM, Stevens GA, Cowan MJ, Danaei G, Lin JK, Paciorek CJ, et al. National, regional, and global trends in body-mass index since 1980: systematic analysis of health examination surveys and epidemiological studies with 960 country-years and 9.1 million participants. Lancet. 2011;377:557-67.

16. Danaei G, Finucane MM, Lin JK, Singh GM, Paciorek CJ, Cowan MJ, et al. National, regional, and global trends in systolic blood pressure since 1980: systematic analysis of health examination surveys and epidemiological studies with 786 country-years and 5.4 million participants. Lancet. 2011;377:568-77.

17. Anand SS, Yusuf S. Stemming the global tsunami of cardiovascular disease. Lancet. 2011;377:529-32.

18. Abegunde DO, Mathers CD, Adam T, Ortegon M, Strong K. The burden and costs of chronic diseases in low-income and middle-income countries. Lancet. 2007;370:1929-38.

19. Stringhini SS, Didon J, Gedeon J, Paccaud F, Bovet P. Declining stroke and myocardial infarction mortality between 1989 and 2010 in a country of the African region. Stroke. (in press). 2012.

20. Rodriguez T, Malvezzi M, Chatenoud L, Bosetti C, Levi F, Negri E, et al. Trends in mortality from coronary heart and cerebrovascular diseases in the Americas: 1970-2000. Heart. 2006;92:453-60.

21. Stuckler D. Population causes and consequences of leading chronic diseases: a comparative analysis of prevailing explanations. Milbank Q. 2008;86:273-326.

22. World Health Organization. The World Health Report - Health system financing. Geneva: WHO; 2010.

23. World Health Organization. Commission on the Social Determinants of Health. Geneva: WHO; 2008.

24. Stuckler D, Basu S, McKee M. Drivers of inequality in Millennium Development Goal progress: a statistical analysis. PLoS Med. 2010;7:e1000241.

25. The World Bank. Toward a healthy and harmonious life in china: stemming the rising tide of non-communicable diseases. Washington DC: The World Bank; 2011.

26. World Economic Forum. Global Risks 2010 - A Global Risk Network Report. Geneva: World Economic Forum; 2010.

27. Nugent R, Feigi AB. Where Have All the donors gone? Scarce donor funding for non-communicable diseases. Washington: Center for Global Development; 2010.

28. World Health Organization. Preventing chronic diseases: a vital investment. Geneva: WHO; 2005.

29. World Health Organization. Mortality and burden of diseases estimates for WHO Member States in 2004. Geneva: WHO; 2009.

30. Mahal A, Karan A, Engelgau, M. The economic implications of noncommunicable diseases for India. HNP Dicussion Paper. Washington DC: The World Bank; 2010. 
31. Asaria P, Chisholm D, Mathers C, Ezzati M, Beaglehole R. Chronic disease prevention: health effects and financial costs of strategies to reduce salt intake and control tobacco use. Lancet. 2007;370:2044-53.

32. Lim SS, Gaziano TA, Gakidou E, Reddy KS, Farzadfar F, Lozano R, et al. Prevention of cardiovascular disease in high-risk individuals in low-income and middle-income countries: health effects and costs. Lancet. 2007;370:2054-62.

33. Nikolic IA, Stanciole AE, Zaydman M. Chronic emergency: Why NCDs matter. Washington DC: The International Bank for Reconstruction and Development - The World Bank; 2011.

34. World Health Organization. Scaling up action against noncommunicable diseases: How much will it cost? Geneva: WHO; 2011.

35. The Oxford Health Alliance. Chronic diseases: an economic perspective. London: The Oxford Health Alliance; 2006.

36. Papadakis S, Moroz I. Population-level interventions for coronary heart disease prevention: what have we learned since the North Karelia project? Curr Opin Cardiol. 2008;23:452-61.

37. Meyers DG, Neuberger JS, He J. Cardiovascular effect of bans on smoking in public places: a systematic review and meta-analysis. J Am Coll Cardiol. 2009;54:1249-55.

38. Zatonski W, Campos H, Willett W. Rapid declines in coronary heart disease mortality in Eastern Europe are associated with increased consumption of oils rich in alpha-linolenic acid. Eur J Epidemiol. 2008;23:3-10.

39. Uusitalo U, Feskens EJ, Tuomilehto J, Dowse G, Haw U, Fareed D, et al. Fall in total cholesterol concentration over five years in association with changes in fatty acid composition of cooking oil in Mauritius: cross sectional survey. BMJ. 1996;313:1044-6.

40. Ford ES, Bergmann MM, Kroger J, Schienkiewitz A, Weikert C, Boeing H. Healthy living is the best revenge: findings from the European Prospective Investigation Into Cancer and Nutrition-Potsdam study. Arch Intern Med. 2009;169:1355-62.

41. Ford ES, Capewell S. Proportion of the decline in cardiovascular mortality disease due to prevention versus treatment: public health versus clinical care. Annu Rev Public Health. 2011;32:5-22.

42. Swinburn BA, Sacks G, Hall KD, McPherson K, Finegood DT, Moodie ML, et al. The global obesity pandemic: shaped by global drivers and local environments. Lancet. 2011;378:804-14.

43. World Health Organization. WHO report on the global tobacco epidemic, 2011: warning about the dangers of tobacco - MPOWER. Geneva: WHO; 2008.

44. Webster JL, Dunford EK, Hawkes C, Neal BC. Salt reduction initiatives around the world. J Hypertens. 2011;29:1043-50.

45. Matsudo VK, Matsudo SM, Araujo TL, Andrade DR, Oliveira LC, Hallal PC. Time trends in physical activity in the state of Sao Paulo, Brazil: 2002-2008. Med Sci Sports Exerc. 2010;42:2231-6. 
46. Bovet P, Gervasoni JP, Mkamba M, Balampama M, Lengeler C, Paccaud F. Low utilization of health care services following screening for hypertension in Dar es Salaam (Tanzania): a prospective population-based study. BMC Public Health. 2008;8:407.

47. Bovet P, Burnier M, Madeleine G, Waeber B, Paccaud F. Monitoring one-year compliance to antihypertension medication in the Seychelles. Bull World Health Organ. 2002;80:33-9.

48. World Health Organization. Strengthening health systems to improve health outcomes. Geneva: WHO; 2007.

49. Lonn E, Bosch J, Teo KK, Pais P, Xavier D, Yusuf S. The polypill in the prevention of cardiovascular diseases: key concepts, current status, challenges, and future directions. Circulation. 2010;122:2078-88.

50. Wald NJ, Law MR. A strategy to reduce cardiovascular disease by more than 80\%. BMJ. 2003;326:1419.

51. Ndindjock R, Gedeon J, Mendis S, Paccaud F, Bovet P. Potential impact of singlerisk-factor versus total risk management for the prevention of cardiovascular events in Seychelles. Bull World Health Organ. 2011;89:286-95.

52. National Institute for Health and Clinical Excellence. Prevention of cardiovascular disease at population level. London: NICE; 2010.

53. Institute of Medecine. Committee on Preventing the Global Health Epidemic of Cardiovascular Disease: Meeting Challenges in Developing Countries. Promoting cardiovascular health in the developing world: a critical challenge to achieve global health. Fuster V, Kelly BB, editors. Washington DC: National Academies Press; 2010.

54. Weintraub WS, Daniels SR, Burke LE, Franklin BA, Goff DC, Jr., Hayman LL, et al. Value of primordial and primary prevention for cardiovascular disease: a policy statement from the american heart association. Circulation. 2011;124:967-90.

55. Cecchini M, Sassi F, Lauer JA, Lee YY, Guajardo-Barron V, Chisholm D. Tackling of unhealthy diets, physical inactivity, and obesity: health effects and cost-effectiveness. Lancet. 2010;376:1775-84.

56. Beaglehole R, Bonita R, Alleyne G, Horton R. NCDs: celebrating success, moving forward. Lancet. 2011;378:1283-4.

57. United Nations General Assembly 66th Session. Political Declaration of the High-level Meeting of the General Assembly on the Prevention and Control of Non-communicable Diseases. A/66/L.1 New York: UN; 2011.

58. Smith R. Health ministers pledge to tackle non-communicable diseases with global action. BMJ. 2011;342:d2796.

59. Marrero SL, Bloom DE, Adashi EY. Noncommunicable diseases: a global health crisis in a new world order. JAMA. 2012;307:2037-8. 